\title{
Inspiratory muscle training is associated with decreased postoperative pulmonary complications: Evidence from randomized trials
}

Xiaoqing Ge, MD, ${ }^{\mathrm{a}}$ Wenjie Wang, MD, ${ }^{\mathrm{b}}$ Lu Hou, MD, ${ }^{\mathrm{a}}$ Kunpeng Yang, MD, PhD, ${ }^{\mathrm{a}}$ and Xianen $\mathrm{Fa}, \mathrm{MD}, \mathrm{PhD}^{\mathrm{c}}$

\section{ABSTRACT}

Objective: To determine whether preoperative inspiratory muscle training was associated with a significant difference in the rate of postoperative pulmonary adverse outcomes in patients undergoing cardiothoracic or upper abdominal surgery using trial sequential analysis to correct for the risk of random errors.

Methods: We systematically reviewed the Excerpta Medica database, PubMed, Web of Science, Cumulative Index to Nursing and Allied Health Literature, and Cochrane Central Register of Controlled Trials for randomized controlled trials evaluating inspiratory muscle training before cardiothoracic or upper abdominal surgery. Outcome measures included postoperative pulmonary complications, length of hospital stay, maximum inspiratory pressure, and quality of life. A random-effects model was used to estimate relative risks with $95 \%$ confidence intervals (CIs). We used trial sequential analysis to calculate a diversityadjusted required information size for meta-analysis.

Results: Thirteen randomized controlled trials were included in the meta-analysis for a total of 784 patients. Compared with the standard care group, the inspiratory muscle training group exhibited significantly decreased postoperative pulmonary complications (risk ratio, $0.59 ; 95 \% \mathrm{CI}, 0.47-0.74$ ). Trial sequential analysis indicated that the cumulative $Z$ curve crossed both the conventional boundary and the trial sequential monitoring boundary for benefit. The length of hospital stay was reduced in the inspiratory muscle training group (mean difference, -1.15 days; $95 \% \mathrm{CI},-2.10$ to 0.20 ), and the maximum inspiratory pressure was significantly improved at the end of the preoperative training (mean difference, $13.66 ; 95 \% \mathrm{CI}, 3.88-23.44)$. The quality of life outcome was unavailable in most of the studies.

Conclusions: Preoperative inspiratory muscle training resulted in significantly improved maximum inspiratory pressure and was associated with decreased postoperative pulmonary complications. ( $\mathrm{J}$ Thorac Cardiovasc Surg

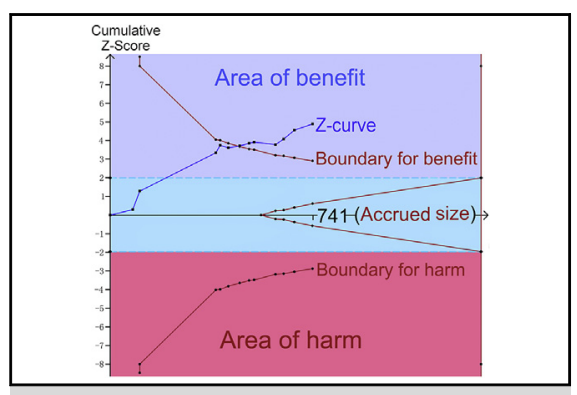

Trial sequential analysis of inspiratory muscle training.

\section{Central Message}

The current study provides high-level evidence in support of using inspiratory muscle training to reduce the incidence of postoperative pulmonary complications.

\section{Perspective}

Preoperative inspiratory muscle training is associated with increased maximum inspiratory pressure and reduced the risk of postoperative pulmonary complications. Our report provides guidelines for clinical practice. Postoperative pulmonary complications may be greatly decreased by inspiratory muscle training.

See Editorial Commentary page 1301. 2018;156:1290-300)

Pulmonary complications are among the most important sources of postoperative morbidity and mortality after

From the ${ }^{a}$ Departments of Thoracic Surgery, and ${ }^{\mathrm{c}}$ Cardiac Surgery, The Second Affiliated Hospital of Zhengzhou University, Zhengzhou, Henan Province, China; and ${ }^{b}$ Second Clinical Medical College of Lanzhou University, Lanzhou, Gansu Province, China.

Received for publication March 15, 2017; revisions received Feb 13, 2018; accepted for publication Feb 23, 2018; available ahead of print April 25, 2018.

Address for reprints: Xiaoqing Ge, MD, Department of Thoracic Surgery, The Second Affiliated Hospital of Zhengzhou University, Jingba Rd 2, Zhengzhou 450014, Henan Province, China (E-mail: geexq@foxmail.com).

$0022-5223 / \$ 36.00$

Copyright (c) 2018 by The American Association for Thoracic Surgery https://doi.org/10.1016/j.jtcvs.2018.02.105 surgery. ${ }^{1}$ These complications are especially prevalent after thoracotomy (19\%-59\%) and upper abdominal surgery $(16 \%-17 \%) .^{2}$ Although numerous factors contribute to postoperative pulmonary complications (PPCs), a potentially modifiable contributing factor is respiratory

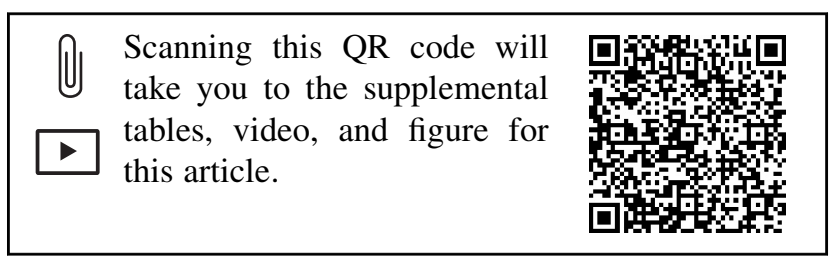




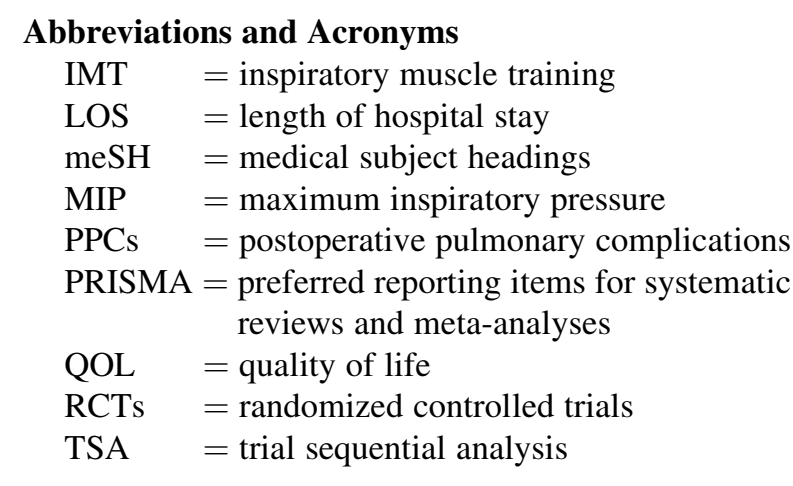

muscle dysfunction, both from surgery-induced changes to the respiratory muscle mechanics and function, but also from preoperative respiratory muscle weakness in some patients. ${ }^{3}$ Over the past 2 decades, surgeons have addressed surgically induced respiratory muscle dysfunction by adopting minimally invasive approaches to the majority of upper abdominal and thoracic operations (Video 1), but less progress has been made in modifying risk preoperatively.

Inspiratory muscle training (IMT) has been used as a nonpharmacologic intervention for respiratory symptoms since the 1980s. ${ }^{4}$ The purpose of IMT is to improve inspiratory muscle strength and endurance. However, no powered trials can confirm that IMT can decrease the incidence of PPCs. Some scholars have reported that IMT can reduce the incidence of PPCs and length of hospital stay (LOS). ${ }^{5}$ Evidence from randomized controlled trials (RCTs) was insufficient to reach definitive conclusions. Therefore, we conducted a meta-analysis of the latest and most convincing evidence to assess the importance of IMT in PPCs. We performed trial sequential analysis (TSA), to determine whether preoperative IMT was associated with a significant difference in the rate of postoperative pulmonary adverse outcomes in patients undergoing cardiothoracic or upper abdominal surgery.

\section{METHODS}

This study was performed in accordance with the preferred reporting items for systematic reviews and meta-analysis (PRISMA) checklists (Table E1). ${ }^{6}$

\section{Literature Search}

We systematically reviewed the bibliographic databases of Excerpta Medica, PubMed, Web of Science, Cumulative Index to Nursing and Allied Health Literature, and Cochrane Central Register of Controlled Trials from inception to September 25, 2016. We conducted electronic searches using exploded medical subject headings (MeSH) terms with the following search strategy: (Preoperative Care [MeSH] OR pre-surgical OR presurgical OR pre-operative OR preoperative) AND (Breathing Exercises [MeSH] OR IMT OR inspiratory muscle train OR respiratory train OR ventilatory train OR pulmonary train OR breathing train OR breathing exercises OR physical therapy modalities OR physiotherapy OR Respiratory therapy) (Table E2).

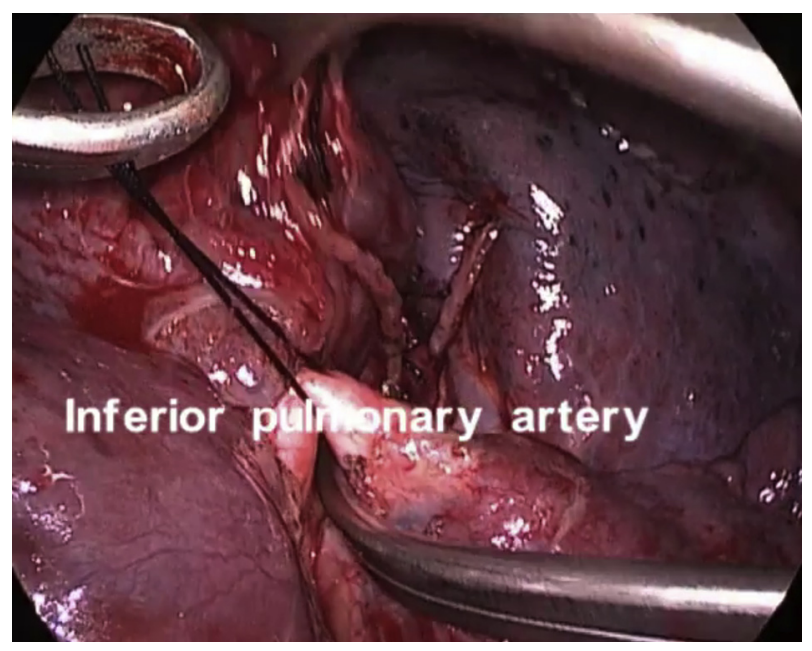

VIDEO 1. Internal intercostal muscle, external intercostal muscle, and diaphragm were involved in the thoracoscopic right lower lobectomy. Video available at: https://www.jtcvs.org/article/S0022-5223(18)30928-0/fulltext.

The search was limited to human subjects, and no language and publication date restrictions were employed. To ensure literature saturation, we manually searched the reference lists of previous reviews, including trials, to identify other potential eligibility tests.

\section{Selection Criteria}

Two authors (X-Q.G. and W-J.W.) performed a preliminary search independently; deleted duplicate records; screened the titles and abstracts for relevance; and identified included, excluded, or uncertain records. In case of uncertainty, full-text articles were acquired to determine eligibility. Any discrepancy was resolved by discussion.

The published RCTs meet the following criteria: population (patients undergoing cardiothoracic or upper abdominal surgery), intervention (IMT), comparison (no preoperative intervention or sham IMT), and $\geq 1$ of the following outcomes: PPCs, maximum inspiratory pressure (MIP), LOS, and quality of life (QOL).

\section{Data Extraction}

Data extraction was performed by X-QG and confirmed independently by 1 of 2 other authors (W-JW and LH). Collected data included year of publication, first author, country, surgery type, sample size, preoperative intervention, baseline of MIP, initial training pressure (started breathing inspiratory muscle strength), IMT time, weeks from initiation training to surgery (training duration), control group, the number of PPCs, LOS, preoperative MIP, and QOL. The extracted data were entered into the spreadsheet. We also sought supplementary appendices of included trials or contacted corresponding authors to verify extracted data and request missing data. Discrepancies were resolved by discussion with collaborators.

The predefined primary outcome was PPCs. Secondary outcomes included the LOS, MIP after intervention, and QOL.

\section{Risk of Bias Assessment}

Two review authors (X-QG and W-JW) independently assessed the risk of bias using the Cochrane risk-of-bias tool. ${ }^{7}$ We reviewed all included studies and scored the following domains as having a high, low or unclear risk of bias: random sequence generation, allocation concealment, blinding of participants and personnel, blinding of outcome assessment, incomplete outcome data, selective reporting, and other bias. Trials with a high risk of bias for any $\geq 1$ key domains were considered to have a high risk of bias, whereas trials with a low risk of bias for all key domains were considered 
to have a low risk of bias. Otherwise, the studies were considered to have an unclear risk of bias. We constructed a risk of bias graph and risk of bias summary figure using Review Manager (RevMan 5.3; The Nordic Cochrane Center, København, Denmark).

\section{Statistical Analysis}

We calculated relative risks (RRs) with $95 \%$ confidence intervals (CIs) for dichotomous outcomes and mean difference (MD) with $95 \%$ CIs for continuous outcomes. Heterogeneity was quantified using the $I^{2}$ statistic. If $I^{2}>50 \%$, indicating significant heterogeneity, a random-effects model was applied; otherwise, a fixed-effects model was used. ${ }^{8}$ We further performed subgroup analyses according to the surgery type, type of PPCs, and IMT time. Sensitivity analysis was performed to estimate the stability of the pooled results. Publication bias was quantified by Egger and Begg tests. Statistical analyses were performed using RevMan version 5.3 and Stata version 13.0 (StataCorp, College Station, Tex).

\section{TSA}

In a single trial, interim analyses increase the risk of type I errors (false-positive results). To avoid type I errors, monitoring boundaries can be used to determine whether a single randomized trial could be terminated prematurely because the $P$ value was sufficiently small to demonstrate the anticipated effect or for futility. Similarly, in a meta-analysis, random errors due to sparse data and repetitive testing of accumulating data increase the risk of type I error. ${ }^{9}$ The method for trial sequential monitoring boundaries that can be applied to meta-analysis to correct the increased risk of random errors is called TSA, which could determine whether the evidence in a meta-analysis is sufficient and persuasive. ${ }^{10,11}$ When the cumulative $Z$ curve crosses the trial sequential monitoring boundary or enters the futility area, sufficient evidence for the anticipated intervention effect may have been potentially achieved, and no further trials are needed. When the $Z$ curve does not cross the boundaries and fulfill the required information size, there is insufficient evidence to arrive at a definitive conclusion. ${ }^{12}$

We used TSA to calculate the diversity-adjusted required information size for this meta-analysis. The size of the information required was calculated using a method similar to that used to calculate a single trial sample size, which was based on the following formula:

$$
I S_{\text {Patients }}=2 \times\left(Z_{1-\alpha / 2}+Z_{1-\beta}\right)^{2} \times 2 \times \sigma^{2} \times \delta^{2}
$$

where $I S_{\text {Patients }}$ is the minimum required information size (number of patients), $\alpha$ is the type I error, $\beta$ is the type II error, $Z_{1-a / 2}$ and $Z_{1-\beta}$ are the $(1-\alpha / 2)$ and $(1-\beta)$ standard normal distribution quantiles, $\delta$ denotes an a priori estimate of the difference between means in two groups, and $\sigma^{2}$ denotes the associated variance. In our TSAs, we used $\alpha=0.05$ (2-sided) and $\beta=0.20$ (power of $80 \%$ ) to estimate the size of required information. The proportion of control events was calculated from the control group and based on an RR reduction of $20 \%$ in PPCs.

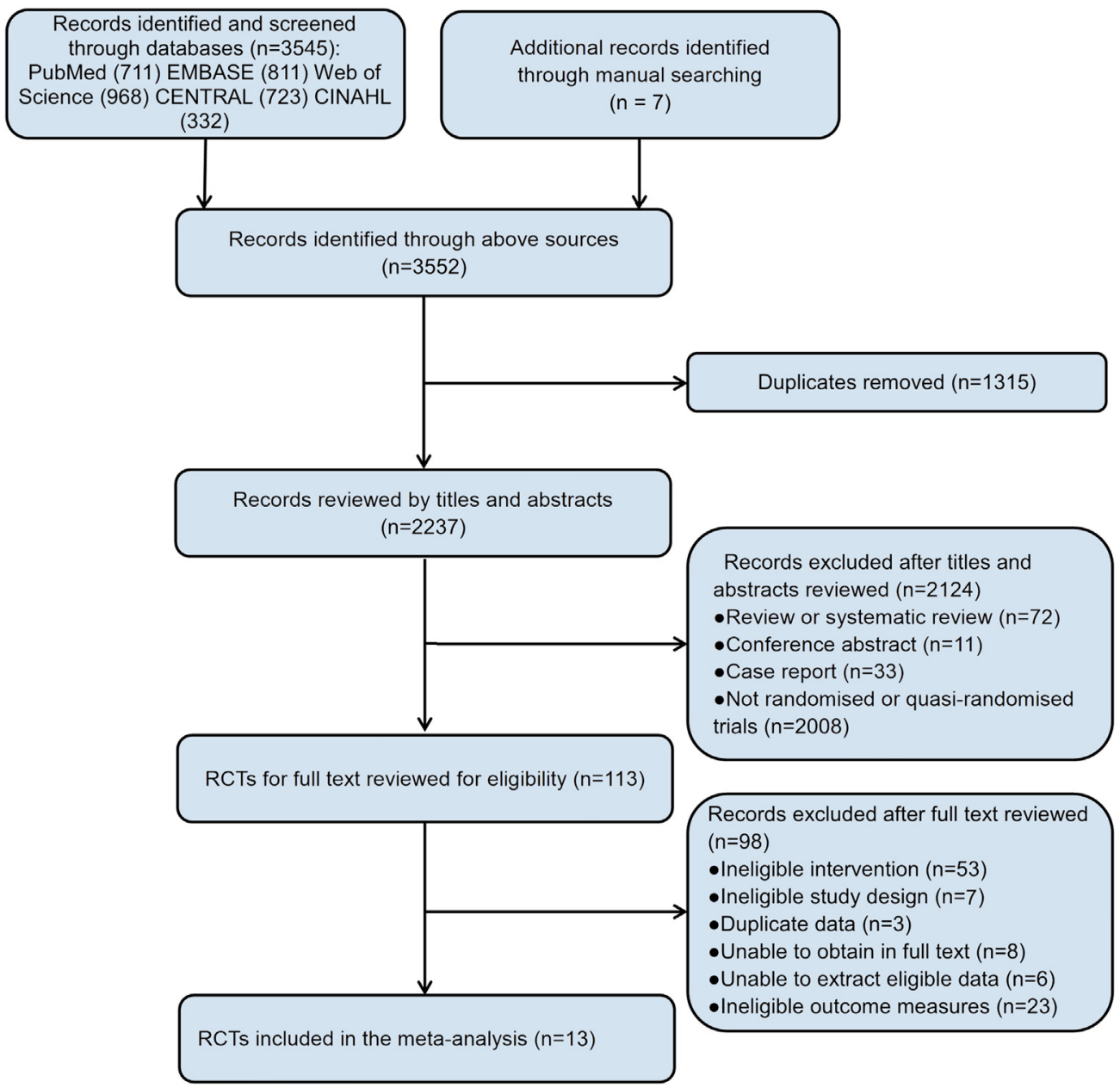

FIGURE 1. Selection of randomized controlled trials $(R C T s)$ for the meta-analysis. EMBASE, Excerpta Medica database; $C E N T R A L$, Cochrane Central Register of Controlled Trials; CINAHL, Cumulative Index to Nursing and Allied Health Literature. 
TABLE 1. Characteristics of included randomized controlled trials

\begin{tabular}{|c|c|c|c|c|c|c|c|c|c|c|c|}
\hline \multirow[b]{2}{*}{ Year } & \multirow[b]{2}{*}{ Reference } & \multirow[b]{2}{*}{ Country } & \multirow[b]{2}{*}{$\begin{array}{c}\text { Surgery } \\
\text { type }\end{array}$} & \multirow[b]{2}{*}{$\begin{array}{c}\text { Sample } \\
\text { size }\end{array}$} & \multirow{2}{*}{$\begin{array}{c}\text { Initial } \\
\text { training } \\
\text { pressure }\end{array}$} & \multirow{2}{*}{$\begin{array}{c}\text { Training } \\
\text { time } \\
(\mathrm{min} / \mathrm{d})\end{array}$} & \multirow{2}{*}{$\begin{array}{c}\text { Sessions } \\
(\mathbf{n} / \mathbf{w k})\end{array}$} & \multirow{2}{*}{$\begin{array}{c}\text { Duration } \\
\text { (wk) }\end{array}$} & \multicolumn{3}{|c|}{ Number of PPCs } \\
\hline & & & & & & & & & Pneumonia & Atelectasis & Others \\
\hline 1998 & $\begin{array}{l}\text { Weiner and } \\
\text { colleagues }^{13}\end{array}$ & Israel & Cardiac & $\begin{array}{l}\text { IMT: } 42 \\
\text { Con: } 42\end{array}$ & $\begin{array}{c}15 \% \text { of } \\
\text { MIP }\end{array}$ & 30 & 6 & $2-4$ & $\begin{array}{l}\text { IMT: } 1 \\
\text { Con: } 3\end{array}$ & N/A & $\begin{array}{l}\text { IMT: } 7 \\
\text { Con: } 6\end{array}$ \\
\hline $2006 a^{*}$ & $\begin{array}{l}\text { Hulzebos and } \\
\text { colleagues }^{14}\end{array}$ & Netherlands & Cardiac & $\begin{array}{l}\text { IMT: } 14 \\
\text { Con: } 12\end{array}$ & $\begin{array}{c}30 \% \text { of } \\
\text { MIP }\end{array}$ & 20 & 7 & $2-4$ & $\begin{array}{l}\text { IMT: } 1 \\
\text { Con: } 1\end{array}$ & $\begin{array}{l}\text { IMT: } 2 \\
\text { Con: } 6\end{array}$ & N/A \\
\hline $2006 b^{*}$ & $\begin{array}{l}\text { Hulzebos and } \\
\text { colleagues }^{15}\end{array}$ & Netherlands & Cardiac & $\begin{array}{l}\text { IMT: } 139 \\
\text { Con: } 137\end{array}$ & $\begin{array}{c}30 \% \text { of } \\
\text { MIP }\end{array}$ & 20 & 7 & $>2$ & $\begin{array}{l}\text { IMT: } 9 \\
\text { Con: } 22\end{array}$ & $\begin{array}{l}\text { IMT: } 14 \\
\text { Con: } 18\end{array}$ & $\begin{array}{l}\text { IMT: } 1 \\
\text { Con: } 8\end{array}$ \\
\hline 2008 & $\begin{array}{l}\text { Dronkers and } \\
\text { colleagues }\end{array}$ & Netherlands & $\begin{array}{l}\text { Upper } \\
\text { abdominal }\end{array}$ & $\begin{array}{l}\text { IMT: } 8 \\
\text { Con: } 8\end{array}$ & $\begin{array}{c}20 \% \text { of } \\
\text { MIP }\end{array}$ & 15 & 6 & $>2$ & N/A & $\begin{array}{l}\text { IMT: } 3 \\
\text { Con: } 8\end{array}$ & N/A \\
\hline 2009 & $\begin{array}{l}\text { Ferreira and } \\
\text { colleagues }^{17}\end{array}$ & Brazil & Cardiac & $\begin{array}{l}\text { IMT: } 15 \\
\text { Con: } 15\end{array}$ & $\begin{array}{c}40 \% \text { of } \\
\text { MIP }\end{array}$ & 15 & 7 & $>2$ & $\begin{array}{l}\text { IMT: } 1 \\
\text { Con: } 0\end{array}$ & N/A & N/A \\
\hline 2010 & $\begin{array}{l}\text { Dronkers and } \\
\text { colleagues }^{18}\end{array}$ & Netherlands & $\begin{array}{l}\text { Upper } \\
\text { abdominal }\end{array}$ & $\begin{array}{l}\text { IMT: } 22 \\
\text { Con: } 20\end{array}$ & $\begin{array}{c}10 \% \text { of } \\
\text { MIP }\end{array}$ & 15 & 7 & $>2$ & $\begin{array}{l}\text { IMT: } 1 \\
\text { Con: } 3\end{array}$ & $\begin{array}{l}\text { IMT: } 5 \\
\text { Con: } 5\end{array}$ & N/A \\
\hline 2010 & $\begin{array}{l}\text { Kulkarni and } \\
\text { colleagues }^{19}\end{array}$ & $\begin{array}{l}\text { United } \\
\text { Kingdom }\end{array}$ & $\begin{array}{l}\text { Upper } \\
\text { abdominal }\end{array}$ & $\begin{array}{l}\text { IMT: } 17 \\
\text { Con: } 17\end{array}$ & $\begin{array}{c}20 \% \text { of } \\
\text { MIP }\end{array}$ & 15 & 7 & $>2$ & $\begin{array}{l}\text { IMT: } 0 \\
\text { Con: } 2\end{array}$ & N/A & N/A \\
\hline 2011 & $\begin{array}{l}\text { Savci and } \\
\quad \text { colleagues }^{20}\end{array}$ & Turkey & Cardiac & $\begin{array}{l}\text { IMT: } 22 \\
\text { Con: } 21\end{array}$ & $\begin{array}{c}15 \% \text { of } \\
\text { MIP }\end{array}$ & 30 & 7 & $5 \mathrm{~d}$ & N/A & N/A & N/A \\
\hline 2012 & $\begin{array}{l}\text { Heynen and } \\
\text { colleagues }^{21}\end{array}$ & Netherlands & Thoracic & $\begin{array}{l}\text { IMT: } 9 \\
\text { Con: } 11\end{array}$ & $\begin{array}{c}30 \% \text { of } \\
\text { MIP }\end{array}$ & 15 & 7 & $>2$ & $\begin{array}{l}\text { IMT: } 1 \\
\text { Con: } 2\end{array}$ & $\begin{array}{l}\text { IMT: } 1 \\
\text { Con: } 2\end{array}$ & N/A \\
\hline 2013 & $\begin{array}{l}\text { Soares and } \\
\text { colleagues }^{23}\end{array}$ & Brazil & $\begin{array}{l}\text { Upper } \\
\text { abdominal }\end{array}$ & $\begin{array}{l}\text { IMT: } 13 \\
\text { Con: } 15\end{array}$ & $\begin{array}{c}15 \% \text { of } \\
\text { MIP }\end{array}$ & 15 & 7 & $2-3$ & $\begin{array}{l}\text { IMT: } 1 \\
\text { Con: } 5\end{array}$ & $\begin{array}{l}\text { IMT: } 2 \\
\text { Con: } 5\end{array}$ & $\begin{array}{l}\text { IMT: } 5 \\
\text { Con: } 1\end{array}$ \\
\hline 2013 & $\begin{array}{l}\text { Dettling and } \\
\text { colleagues }^{22}\end{array}$ & Netherlands & Thoracic & $\begin{array}{l}\text { IMT: } 39 \\
\text { Con: } 39\end{array}$ & $\begin{array}{c}30 \% \text { of } \\
\text { MIP }\end{array}$ & 20 & 7 & $>2$ & $\begin{array}{l}\text { IMT: } 7 \\
\text { Con: } 9\end{array}$ & N/A & $\begin{array}{l}\text { IMT: } 6 \\
\text { Con: } 6\end{array}$ \\
\hline 2014 & $\begin{array}{l}\text { Van Adrichem } \\
\text { and } \\
\text { colleagues }^{24}\end{array}$ & Netherlands & Thoracic & $\begin{array}{l}\text { IMT: } 20 \\
\text { Con: } 19\end{array}$ & $\begin{array}{c}30 \% \text { of } \\
\text { MIP }\end{array}$ & 20 & 7 & $2-4$ & $\begin{array}{l}\text { IMT: } 3 \\
\text { Con: } 8\end{array}$ & N/A & $\begin{array}{l}\text { IMT: } 1 \\
\text { Con: } 3\end{array}$ \\
\hline 2016 & $\begin{array}{l}\text { Brocki and } \\
\text { colleagues }^{25}\end{array}$ & Denmark & Thoracic & $\begin{array}{l}\text { IMT: } 34 \\
\text { Con: } 34\end{array}$ & $\begin{array}{c}30 \% \text { of } \\
\text { MIP }\end{array}$ & 15 & 7 & 2 & $\begin{array}{l}\text { IMT: } 2 \\
\text { Con: } 7\end{array}$ & $\begin{array}{l}\text { IMT: } 0 \\
\text { Con: } 1\end{array}$ & $\begin{array}{l}\text { IMT: } 2 \\
\text { Con: } 0\end{array}$ \\
\hline
\end{tabular}

PPCs, Postoperative pulmonary complications; IMT, inspiratory muscle training; Con, control group; MIP, maximum inspiratory pressure; N/A, not available. *Hulzebos and colleagues 2006a sample size was 26; Hulzebos and colleagues 2006b sample size was 276.

O’Brian-Fleming boundaries and TSA software version 0.9 (Copenhagen Trial Unit, Center for Clinical Intervention Research, Rigshospitalet, Copenhagen, Denmark) were used for these analyses.

\section{RESULTS}

\section{Trial Selection}

A PRISMA statement flowchart presents the process of literature screening, study selection, and reasons for exclusion (Figure 1). Our initial search identified 3545 relevant studies, and we manually retrieved 7 studies. After deleting duplicated studies and filtering titles and abstracts, 113 articles met the inclusion criteria. After reviewing the full text, 13 RCTs were finally included in the meta-analysis. ${ }^{13-25}$

\section{Trials Characteristics}

The main characteristics included in the trials are summarized in Table 1. These trials were published from 1998 to 2016. Population sizes ranged from 16 to 276, with a total of 784 patients. Five studies $(n=459)$ investigated participants undergoing cardiac surgery, ${ }^{13-15,17,20} 4$ studies $(n=205)$ investigated those undergoing thoracic surgery, ${ }^{21,22,24,25}$ and 4 studies $(\mathrm{n}=120)$ investigated participants undergoing upper abdominal surgery. ${ }^{16,18,19,23}$ The patients started breathing at a resistance equal to $10 \%$ to $40 \%$ of their maximal inspiratory mouth pressure. The participants trained daily, 6 or 7 times a week, for at least 5 days before surgery, and each IMT session lasted 15 to 30 minutes. IMT time was 15 minutes daily in 7 studies, ${ }^{16-19,21,23,25} 20$ minutes in 4 studies, ${ }^{14,15,22,24}$ and 30 minutes in 2 studies. ${ }^{13,20}$ The mean MIP before intervention across all included studies ranged from 62.0 to $93.5 \mathrm{~cm} \mathrm{H}_{2} \mathrm{O}$. The values for the intervention group and control group increased from 72.0 to $104.5 \mathrm{~cm} \mathrm{H}_{2} \mathrm{O}$ and from 57.2 to $113.0 \mathrm{~cm} \mathrm{H}_{2} \mathrm{O}$, respectively, before the operation (Table 2). All studies used a threshold-loading device to provide IMT. ${ }^{26}$ 
TABLE 2. Summary for intervention and changes of maximum inspiratory pressure (MIP)

\begin{tabular}{|c|c|c|c|c|c|c|c|}
\hline \multirow[b]{2}{*}{ Year } & \multirow[b]{2}{*}{ Reference } & \multirow{2}{*}{$\begin{array}{l}\text { Preoperative } \\
\text { intervention }\end{array}$} & \multirow[b]{2}{*}{ Control } & \multicolumn{2}{|c|}{$\begin{array}{c}\text { MIP of IMT } \\
\text { group }\left(\mathrm{cm} \mathrm{H}_{2} \mathrm{O}\right)\end{array}$} & \multicolumn{2}{|c|}{$\begin{array}{l}\text { MIP of control } \\
\text { group }\left(\mathrm{cm} \mathrm{H}_{2} \mathrm{O}\right)\end{array}$} \\
\hline & & & & Baseline & $\overline{\text { Preoperation }}$ & Baseline & Preoperation \\
\hline 1998 & Weiner and colleagues ${ }^{13}$ & Threshold IMT & $\begin{array}{c}\text { No preoperative } \\
\text { intervention }\end{array}$ & $88.0(5.9)$ & $101.9(7.8)$ & $91.2(6.8)$ & $94.1(6.2)$ \\
\hline 2008 & Dronkers and colleagues ${ }^{16}$ & Threshold IMT & $\begin{array}{c}\text { No preoperative } \\
\text { intervention }\end{array}$ & $68.0(19.0)$ & $72.0(22.0)$ & $83.0(15.0)$ & $80.0(24.0)$ \\
\hline 2010 & Dronkers and colleagues ${ }^{18}$ & Threshold IMT & Usual care & $78.0(33.0)$ & $92.0(26.0)$ & $93.0(25.0)$ & $98.0(26.0)$ \\
\hline 2011 & Savci and colleagues ${ }^{20}$ & $\begin{array}{l}\text { Threshold IMT and } \\
\text { usual preoperative care }\end{array}$ & Usual care & $82.6(29.3)$ & $95.5(30.3)$ & $84.6(17.3)$ & $57.2(19.5)$ \\
\hline 2013 & Soares and colleagues ${ }^{23}$ & $\begin{array}{l}\text { Threshold IMT and } \\
\text { usual preoperative care }\end{array}$ & $\begin{array}{l}\text { No preoperative } \\
\text { intervention }\end{array}$ & $62.0(24.4)$ & $88.0(27.4)$ & $72.0(26.7)$ & $64.0(32.6)$ \\
\hline 2014 & $\begin{array}{l}\text { Van Adrichem and } \\
\text { colleagues }^{24}\end{array}$ & Threshold IMT & $\begin{array}{l}\text { Sham threshold } \\
\text { IMT }\end{array}$ & $93.5(38.2)$ & $104.5(30.2)$ & $84.0(20.0)$ & $113.0(29.6)$ \\
\hline $2006 a^{*}$ & Hulzebos and colleagues ${ }^{14}$ & $\begin{array}{l}\text { Threshold IMT and } \\
\text { usual preoperative care }\end{array}$ & Usual care & $64.6(15.8)$ & $87.6(29.1)$ & $66.8(26.3)$ & $76.8(27.9)$ \\
\hline $2006 b^{*}$ & Hulzebos and colleagues ${ }^{15}$ & $\begin{array}{l}\text { Threshold IMT and } \\
\text { usual preoperative care }\end{array}$ & Usual care & $81.1(29.5)$ & $95.6(31.6)$ & $80.3(31.4)$ & $79.5(31.3)$ \\
\hline 2016 & Brocki and colleagues ${ }^{25}$ & $\begin{array}{l}\text { Threshold IMT and } \\
\text { physiotherapy treatment }\end{array}$ & Usual care & $82.8(26.8)$ & $0.2(17.9) \dagger$ & $78.5(29.5)$ & $4.3(15.1) \dagger$ \\
\hline
\end{tabular}

$M I P$, Maximum inspiratory pressure; IMT, inspiratory muscle training. *Hulzebos and colleagues 2006a sample size was 26; Hulzebos and colleagues $2006 \mathrm{~b}$ sample size was 276 $\dagger$ Change from baseline.

\section{Risk of Bias Assessment}

In the present study, we used the Cochrane risk of bias tool to evaluate the quality of the included studies, and the results were presented in Figure E1. Most of the included studies described the details regarding random sequence generation, blinding of outcome assessment, incomplete outcome data, and selective reporting. . $^{4,15,20,24,25}$ Some studies did not mention allocation concealment, blinding of participants and personnel, or random sequence generation. ${ }^{13,17,21,22}$ The other indexes of bias typically lacked specific descriptions in the included clinical studies. ${ }^{16,18,19,22,23}$

\section{Preoperative IMT Versus Standard Care}

Primary outcomes. We pooled the data of PPCs in the meta-analysis according to the original authors' definitions (Table 3); the definition of PPCs by Kroenke and colleagues ${ }^{27}$ is shown in Table E3. Twelve trials totaling 741 patients provided data on PPCs. ${ }^{13-19,21-25}$ Compared with standard care, IMT was associated with a significant decrease in PPCs (RR, 0.59; 95\% CI, 0.47-0.74; $P<.00001 ; I^{2}=0 \%$ ) (Figure 2). TSA indicated that the cumulative $Z$ curve crossed the conventional boundary for benefit and the trial sequential monitoring boundary for benefit, which established sufficient and persuasive evidence for the role of IMT on PPCs (Figure 3).

Van Adrichem and colleagues ${ }^{24}$ reported "high intensity IMT group" versus "endurance IMT group" rather than usual care, and the incidence of PPCs was approximately 3 -fold reduced for the high-intensity group.

Subgroup analyses were further performed based on various variables. When stratified according to surgery type, the pooled RRs of the thoracic, cardiac, and upper abdominal subgroups for PPCs were 0.44 (95\% CI, 0.23$0.84 ; P=.01), 0.57$ (95\% CI, $0.40-0.81 ; P=.0002)$, and 0.70 (95\% CI, 0.50-0.99; $P=.04$ ), respectively. Stratified according to type of PPCs, the pooled RRs of pneumonia $^{13-15,17-19,21-25}$ and atelectasis ${ }^{14-16,18,21,23,25}$ were 0.44 (95\% CI, 0.29-0.67; $P=.0001)$ and 0.60 (95\% CI, $0.40-0.91 ; P<.00001)$, respectively. Stratified according to IMT time, the RRs for 15 and 20 minutes were 0.62 (95\% CI, 0.43-0.91; $P=.01)$ and 0.54 (95\% CI, 0.40$0.74 ; P<.0001)$, respectively. The results of subgroup analyses are summarized in Table 4.

For the meta-analysis of preoperative IMT on PPCs, the pooled RR ranged from 0.55 (95\% CI, 0.43-0.71) to 0.63 (95\% CI, 0.48-0.84). Sensitivity analysis indicated that the results were stable, and no articles influenced the pooled RR. The Begg funnel plot for PPCs was symmetrical, and the Egger test $P$ value was .707 (95\% CI, -1.56 to 1.10$)$. These results indicated that no publication bias existed in the current study.

Secondary outcomes. Eight trials totaling 592 patients reported data on length of hospital stay. ${ }^{14,15,18,20-22,24,25}$ LOS in the IMT group was significantly reduced compared with the control group (MD, -1.15 days; 95\% CI, -2.10 
TABLE 3. The definition of postoperative pulmonary complications (PPCs)

\begin{tabular}{|c|c|c|}
\hline Year & Reference & Definition of PPCs \\
\hline 1998 & Weiner and colleagues ${ }^{13}$ & Not mentioned, PPCs were detected by chest radiography \\
\hline $2006 a^{*}$ & Hulzebos and colleagues $^{14}$ & $\begin{array}{l}\text { Defined according to clinical (symptoms and physical examinations) and radiologic criteria such as } \\
\text { bronchitis, atelectasis, and pneumonia. When there were only radiologic alterations without clinical } \\
\text { symptoms, the complications were considered to be subclinical }\end{array}$ \\
\hline $2006 b^{*}$ & Hulzebos and colleagues $^{15}$ & $\begin{array}{l}\text { An ordinal scale of } 1-4 \text {, using the operational definition of Kroenke and colleagues }{ }^{27} \text {. They defined a } \\
\text { clinically significant PPC as } 2 \text { or more items in the grade } 2 \text { complications or } 1 \text { item in the grade } 3 \text { or } 4 \\
\text { complications. When only abnormal radiologic findings were found, without clinical symptoms, the } \\
\text { complications were considered subclinical }\end{array}$ \\
\hline 2008 & Dronkers and colleagues $^{16}$ & $\begin{array}{l}\text { Operationalized as atelectasis. A blinded radiologist evaluated radiographs of the lung base for the } \\
\text { presence of atelectasis }\end{array}$ \\
\hline 2009 & Ferreira and colleagues ${ }^{17}$ & Not mentioned \\
\hline 2010 & Dronkers and colleagues $^{18}$ & $\begin{array}{l}\text { Classified as hypoxia (defined as need for additional oxygen), atelectasis (diagnosed by a radiologist), } \\
\text { pneumonia (defined according to classification of Arozullah and colleagues }{ }^{28} \text {, and respiratory failure } \\
\text { (defined as need for artificial respiration) }\end{array}$ \\
\hline 2010 & Kulkarni and colleagues ${ }^{19}$ & Not mentioned \\
\hline 2011 & Savci and colleagues ${ }^{20}$ & $\begin{array}{l}\text { Chest X-ray analysis was done by a cardiothoracic specialist. The presence of atelectasis, pleural effusion, } \\
\text { and/or lung consolidation was recorded. When there were only radiologic alterations without clinical } \\
\text { symptoms; the complications were considered to be subclinical }\end{array}$ \\
\hline 2012 & Heynen and colleagues ${ }^{21}$ & Not mentioned \\
\hline 2013 & Soares and colleagues ${ }^{23}$ & $\begin{array}{l}\text { Defined as pulmonary complications treated and noted in medical records until the seventh postoperative } \\
\text { day, were: respiratory failure, as characterized by a need for endotracheal intubation and mechanical } \\
\text { ventilation; atelectasis, pleural effusion, or pneumothorax, as diagnosed on chest radiographs; or } \\
\text { pneumonia, on the basis of clinical, laboratory, and imaging findings and institution of antibiotic therapy }\end{array}$ \\
\hline 2013 & Dettling and colleagues ${ }^{22}$ & $\begin{array}{l}\text { Postoperative pneumonia was defined as a new infiltrative abnormality on chest radiograph accompanied } \\
\text { by purulent sputum or fever in combination with the necessity of antibiotic treatment. The duration of } \\
\text { mechanical ventilation, reintubation caused by respiratory failure }\end{array}$ \\
\hline 2014 & Van Adrichem and colleagues ${ }^{24}$ & PPCs were recorded using the criteria described by Kroenke and colleagues ${ }^{27}$ \\
\hline 2016 & Brocki and colleagues ${ }^{25}$ & $\begin{array}{l}\text { PPC was classified as } 1 \text { (minor) to } 3 \text { (severe), and a clinically relevant PPC was defined as two or more } \\
\text { items in the grade } 1 \text { complication or one item in the grade } 2 \text { or } 3 \text { complication, which was modified from } \\
{\text { Kroenke et } \mathrm{al}^{27} \text { and Hulzebos and colleagues }}^{14}\end{array}$ \\
\hline
\end{tabular}

*Hulzebos and colleagues 2006a sample size was 26; Hulzebos and colleagues 2006b sample size was 276.

to $0.20 ; P=.02 ; I^{2}=14 \%$ ) (Figure 4). TSA revealed that the cumulative $Z$ curve crossed the conventional boundary for benefit, but did not cross the trial sequential monitoring, suggesting that further trials were required (Figure 5).
Ten trials evaluated the effects of preoperative IMT on MIP. $^{13-18,20,22,25}$ Compared with baseline measures, IMT significantly improved MIP (MD, $13.66 ; 95 \% \mathrm{CI}$, $3.88-23.44 ; P=.0002 ; I^{2}=73 \%$ ) (Figure 6).

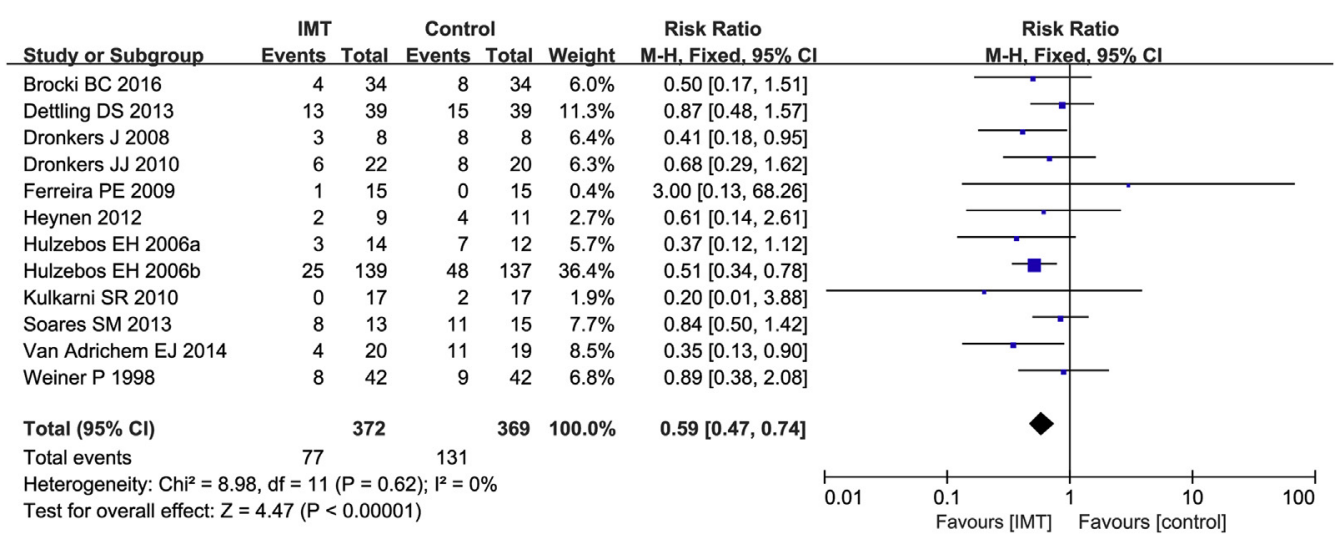

FIGURE 2. Forest plot of the effect of inspiratory muscle training (IMT) on postoperative pulmonary complications. $M$ - $H$, Mantel-Haenszel; $C I$, confidence interval. 


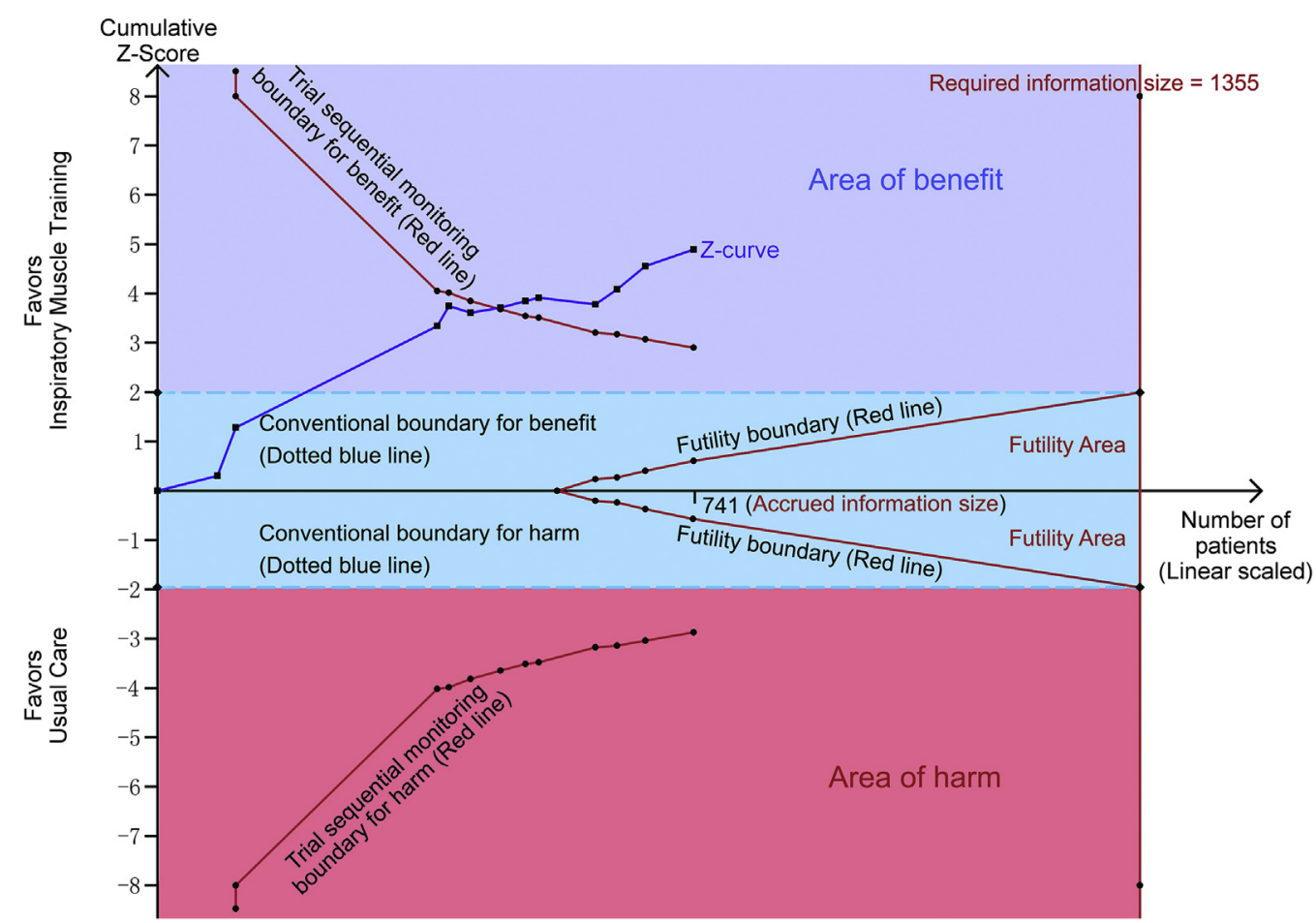

FIGURE 3. Trial sequential analysis of 12 trials comparing inspiratory muscle training with standard care for postoperative pulmonary complications (scaled trial distance). Trial sequential analysis of 12 trials (blue square filled icons) illustrating that the cumulative $Z$ curve crossed both the conventional boundary for benefit and the trial sequential monitoring boundary for benefit. A diversity-adjusted required information size of 1355 patients was calculated using $\alpha=0.05$ (2-sided) and $\beta=0.20$ (power of $80 \%$ ) for an anticipated relative risk reduction of $20 \%$.

The QOL outcome was unavailable in most studies. Three trials reported QOL results, 1 trial reported that IMT did not significantly influence QOL, a second trial reported improvement in the QOL sleep dimension, and the third stated that the QOL metrics were still under evaluation and not reported. ${ }^{18,20,21}$ Due to the small number of studies and included patients, a meta-analysis of the QOL measures was not possible.

\section{DISCUSSION}

Dysfunction of the respiratory muscles from surgery may lead to a reduction in vital capacity, tidal volume, and total lung capacity as well as insufficient cough, which may cause atelectasis in the basal lung segments and a reduction in functional residual capacity. The efforts to increase MIP can increase respiratory muscle strength and improve functional capacity, but the MIP may be meaningless if the baseline levels are good to start. ${ }^{29}$ Of note, a significant effect of IMT associated with decreased PPCs was demonstrated from the meta-analysis despite the fact that 1 of the studies included 2 intervention groups (a high-intensity and endurance group) rather than usual care. ${ }^{24}$ This finding suggests that the effect of IMT on improving pulmonary outcomes may be even stronger than the current analysis suggests.

TABLE 4. Subgroup analyses about postoperative pulmonary complications (PPCs)

\begin{tabular}{|c|c|c|c|c|c|}
\hline \multirow[b]{2}{*}{ Item } & \multicolumn{2}{|c|}{ Test for heterogeneity } & \multicolumn{2}{|c|}{ Test for overall effect } & \multirow[b]{2}{*}{ Risk ratio ( $95 \%$ confidence interval) } \\
\hline & $I^{2}$ & $P$ value & $Z$ & $P$ value & \\
\hline \multicolumn{6}{|l|}{ Surgery type } \\
\hline Thoracic $21,22,24,25$ & 0 & .78 & 2.49 & .01 & $0.44(0.23-0.84)$ \\
\hline Cardiac $^{13-15,17}$ & 0 & .4 & 3.17 & .002 & $0.57(0.40-0.81)$ \\
\hline Upper abdominal $^{16,18,19,23}$ & 0 & .53 & 2.04 & .04 & $0.70(0.50-0.99)$ \\
\hline \multicolumn{6}{|l|}{ Type of PPCs } \\
\hline Pneumonia ${ }^{13-15,17-19,21-25}$ & 0 & .91 & 3.83 & .0001 & $0.44(0.29-0.67)$ \\
\hline Atelectasis $^{14-16,18,21,23,25}$ & 0 & .78 & 2.42 & .02 & $0.60(0.40-0.91)$ \\
\hline \multicolumn{6}{|l|}{ Training time } \\
\hline $15 \min ^{16-19,21,23,25}$ & 0 & .69 & 2.45 & .01 & $0.62(0.43-0.91)$ \\
\hline $20 \min ^{14,15,22,24}$ & 21 & .29 & 3.89 & $<.0001$ & $0.54(0.40-0.74)$ \\
\hline
\end{tabular}

PPCs, Postoperative pulmonary complications. 


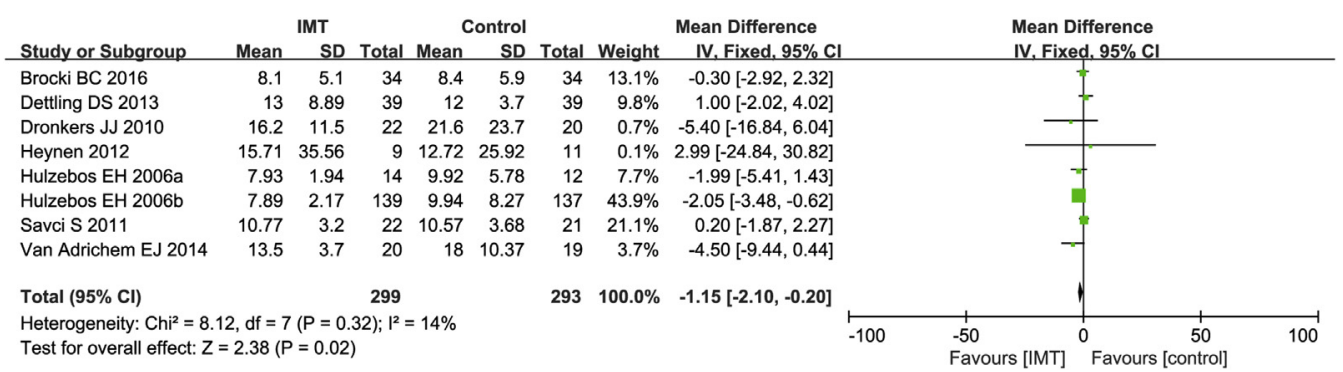

FIGURE 4. Forest plot of the effect of inspiratory muscle training (IMT) on length of hospital stay. SD, Standard deviation; $C I$, confidence interval; $I V$, inverse variance.

\section{Main Findings}

Our meta-analysis comprehensively and systematically reviewed the currently available literature and revealed that IMT was associated with a significant reduction in PPCs in patients undergoing cardiac, thoracic, and upper abdominal surgery; the evidence of benefit was consistent in subgroup analyses and was confirmed by TSA; preoperative IMT was uncertain with regard to reducing hospital stay, and more research is needed; and the MIP can be increased at the end of the preoperative IMT.

\section{Comparison With Other Meta-Analyses}

Two additional meta-analyses have been published on this subject (Table 5). ${ }^{5,30}$ The main findings of our meta-analysis were similar to previous meta-analyses. However, some obvious differences are noted. First, our meta-analysis included 13 trials with 784 patients. Our meta-analysis is the most recent, and it generally agrees with and further reinforces results of previous meta-analyses. Other meta-analyses also assessed the effect of preoperative respiratory muscle training on postoperative complications and reported results similar to ours. ${ }^{31,32}$ Second, we further applied TSA to provide more conservative estimates. TSA provided information regarding size, the threshold for a statistically significant treatment effect, and the threshold for futility. Conclusions using TSA were more reliable compared with traditional meta-analysis techniques.

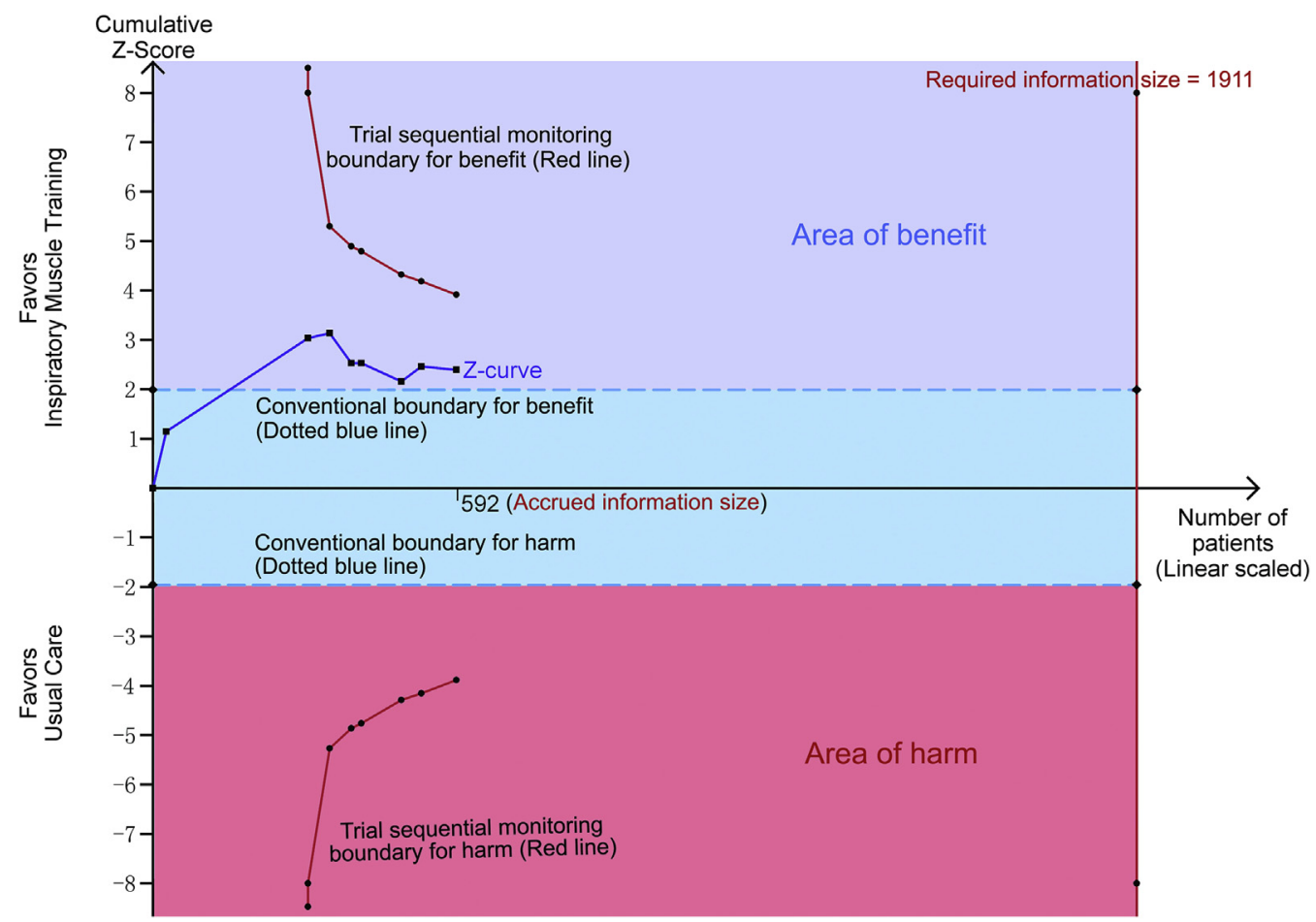

FIGURE 5. Trial sequential analysis of 8 trials comparing inspiratory muscle training with standard care for length of hospital stay (scaled trial distance). Trial sequential analysis of 8 trials (blue square filled icons) illustrating that the cumulative $Z$ curve crossed the conventional boundary for benefit, but did not cross the trial sequential monitoring boundary for benefit. A diversity-adjusted required information size of 1911 patients was calculated using $\alpha=0.05$ (2-sided) and $\beta=0.20$ (power of $80 \%$ ) for an anticipated relative risk reduction of $20 \%$. 


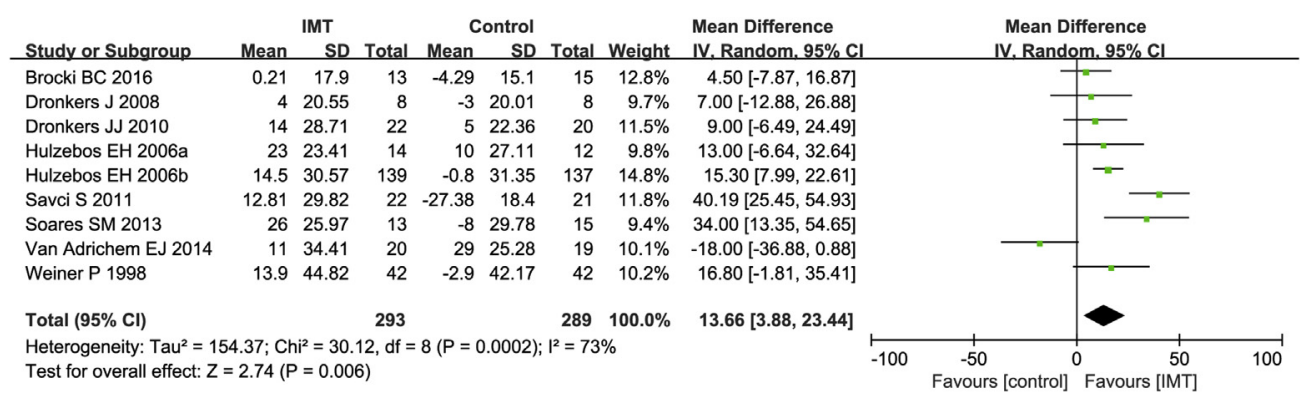

FIGURE 6. Forest plot of the effect of inspiratory muscle training (IMT) on maximal inspiratory pressure after intervention. $S D$, Standard deviation; $C I$, confidence interval; $I V$, inverse variance.

\section{Implications for Clinical Practice}

Our meta-analysis demonstrated that IMT was associated with a decrease in PPCs in patients undergoing thoracic, cardiac, and upper abdominal surgery. This result is well characterized by our TSA. IMT can increase the MIP and may reduce LOS. Subgroup analysis of PPCs revealed that preoperative IMT for 15 minutes or more per day was effective. All of the training periods for reducing PPCs were $>2$ weeks. Thus, we recommend preoperative IMT for $>2$ weeks.

\section{Strengths and Limitations}

A major strength of this meta-analysis is that the analysis is consistent with the recommendations of the PRISMA guidelines and the Cochrane Collaboration; however, we did not register our study protocol. To increase the robustness of this meta-analysis, we applied TSA to assess the effects of random errors and repetitive testing. As a useful approach, TSA is introduced to calculate the required information size for this meta-analysis with the adaptation of monitoring boundaries. In addition, we used TSA to estimate whether a sufficient level of evidence was achieved and whether further trials were necessary. For the results on the role of IMT in PPCs, the cumulative
$Z$ curve did not exceed the required sample size but crossed the trial sequential monitoring boundaries, indicating that our conclusions are supported by a sufficient level of evidence.

The limitations of our meta-analysis should also be noted. First, although the overall analysis suggests that the role of IMT on PPCs is definite, further studies to examine the influence of each operation type are needed to determine efficacy and cost-benefits. Second, in the secondary outcome, the QOL data cannot be completely extracted. Most studies did not report the exact information or data required; thus, a QOL meta-analysis was not conducted. Third, in the subgroup analysis of the PPCs, only 1 study included a training period that was $>30$ minutes, so the subgroup, including a $>30$-minute training session was not analyzed. Fourth, based on this study we are not certain whether minimally invasive surgery would eliminate the effect that patients who had IMT had significantly fewer PPCs after open surgery but not after thoracosopy or laparoscopy because the proportions of laparoscopic or thoracoscopic versus open surgeries were not clear. We contacted all the corresponding authors of original studies to clarify the proportions. Only 1 author ${ }^{19}$ replied (from memory) that 10 to 11 patients had

TABLE 5. Comparison with previous meta-analyses

\begin{tabular}{|c|c|c|c|}
\hline Study element & Mans and colleagues $2015^{30}$ & Katsura and colleagues $2015^{5}$ & Current meta-analysis \\
\hline No. of randomized controlled trials & 8 & 12 & 13 \\
\hline No. of participants & 295 & 695 & 784 \\
\hline Search strategy until year & 2013 & 2014 & 2016 \\
\hline PPCs, RR $(95 \% \mathrm{CI})$ & $0.48(0.26-0.89)$ & Not reported & $0.59(0.47-0.74)$ \\
\hline Pneumonia, RR (95\% CI) & Not reported & $0.45(0.26-0.77)$ & $0.44(0.29-0.67)$ \\
\hline Atelectasis, RR (95\% CI) & Not reported & $0.53(0.34-0.82)$ & $0.60(0.40-0.91)$ \\
\hline LOS, MD $(95 \%$ CI $)$ & $-1.66(-3.64$ to 0.31$)$ & $-1.33(-2.53$ to -0.13$)$ & $-1.15(-2.10$ to -0.20$)$ \\
\hline MIP, MD (95\% CI) & $15(9-21)$ & Not reported & $14.15(9.54-18.75)$ \\
\hline Trial sequential analysis & Not applied & Not applied & Applied \\
\hline Implications for clinical practice & Vaguely & Vaguely & Clearly \\
\hline
\end{tabular}

$\overline{P P C S}$, Postoperative pulmonary complications; $R R$, risk ratio; $C I$, confidence interval; $L O S$, length of hospital stay; $M D$, mean difference; $M I P$, maximum inspiratory pressure. 
laparoscopy surgery and the original data had been destroyed, so the details of thoracosopy versus thoracotomy and laparoscopy versus laparotomy were not analyzed. Fifth, a major limitation is that we did not include or control for important pretreatment variables that could influence outcomes, such as preoperative pulmonary function tests. Sixth, the minimally clinically important difference for MIP has not been established, which limits the conclusions that can be made regarding the clinical significance of our finding.

\section{CONCLUSIONS}

IMT when performed for 15 minutes daily or longer is associated with increased MIP and is associated with reduced the risk of PPCs.

\section{Conflict of Interest Statement}

Authors have nothing to disclose with regard to commercial support.

\section{References}

1. Anselmi A, Verhoye JP. Prevention of postoperative pulmonary complications and aggregation of marginal gains. J Thorac Cardiovasc Surg. 2017;153: 735-6.

2. Co CG, Quintero DA, Honig EG. Postoperative care and complications after thoracic surgery. JAMA. 2010;100:21-6.

3. Mitchell CK, Smoger SH, Pfeifer MP, Vogel RL, Pandit MK, Donnelly PJ, et al. Multivariate analysis of factors associated with postoperative pulmonary complications following general elective surgery. Arch Surg. 1998;133:194-8.

4. Geddes EL, O'Brien K, Reid WD, Brooks D, Crowe J. Inspiratory muscle training in adults with chronic obstructive pulmonary disease: an update of a systematic review. Respir Med. 2008;102:1715-29.

5. Katsura M, Kuriyama A, Takeshima T, Fukuhara S, Furukawa TA. Preoperative inspiratory muscle training for postoperative pulmonary complications in adults undergoing cardiac and major abdominal surgery. Cochrane Database Syst Rev 2015;10:CD010356.

6. Knobloch K, Yoon U, Vogt PM. Preferred reporting items for systematic reviews and meta-analyses (PRISMA) statement and publication bias. $J$ Craniomaxillofac Surg. 2011;39:91-2.

7. Higgins JP, Altman DG, Gotzsche PC, Juni P, Moher D, Oxman AD, et al. The Cochrane Collaboration's tool for assessing risk of bias in randomised trials. BMJ. 2011;343:d5928.

8. Tufanaru C, Munn Z, Stephenson M, Aromataris E. Fixed or random effects meta-analysis? Common methodological issues in systematic reviews of effectiveness. Int J Evid-Based Healthc. 2015;13:196-207.

9. Borm GF, Donders AR. Updating meta-analyses leads to larger type I errors than publication bias. J Clin Epidemiol. 2009;62:825-30.

10. Wetterslev J, Thorlund K, Brok J, Gluud C. Trial sequential analysis may establish when firm evidence is reached in cumulative meta-analysis. J Clin Epidemiol. 2008;61:64-75.

11. Brok J, Thorlund K, Wetterslev J, Gluud C. Apparently conclusive meta-analyses may be inconclusive - trial sequential analysis adjustment of random error risk due to repetitive testing of accumulating data in apparently conclusive neonatal meta-analyses. Int J Epidemiol. 2009;38:287-98.

12. Brok J, Thorlund K, Gluud C, Wetterslev J. Trial sequential analysis reveals insufficient information size and potentially false positive results in many meta-analyses. J Clin Epidemiol. 2008;61:763-9.

13. Weiner P, Zeidan F, Zamir D, Pelled B, Waizman J, Beckerman M, et al. Prophylactic inspiratory muscle training in patients undergoing coronary artery bypass graft. World J Surg. 1998;22:427-31.
14. Hulzebos EH, Helders PJ, Favie NJ, De Bie RA, Brutel De La Riviere A, Van Meeteren NL. Preoperative intensive inspiratory muscle training to prevent postoperative pulmonary complications in high-risk patients undergoing $\mathrm{CABG}$ surgery: a randomized clinical trial. JAMA 2006;296:1851-7.

15. Hulzebos EH, Van Meeteren NL, Van Den Buijs BJ, De Bie RA, Brutel De La Riviere A, Helders PJ. Feasibility of preoperative inspiratory muscle training in patients undergoing coronary artery bypass surgery with a high risk of postoperative pulmonary complications: a randomized controlled pilot study. Clin Rehabil. 2006;20:949-59.

16. Dronkers J, Veldman A, Hoberg E, Van Der Waal C, Van Meeteren N. Prevention of pulmonary complications after upper abdominal surgery by preoperative intensive inspiratory muscle training: a randomized controlled pilot study. Clin Rehabil. 2008;22:134-42.

17. Ferreira PE, Rodrigues AJ, Evora PR. Effects of an inspiratory muscle rehabilitation program in the postoperative period of cardiac surgery. Arq Bras Cardiol. 2009;92:275-82.

18. Dronkers JJ, Lamberts H, Reutelingsperger IM, Naber RH, DronkersLandman CM, Veldman A, et al. Preoperative therapeutic programme for elderly patients scheduled for elective abdominal oncological surgery: a randomized controlled pilot study. Clin Rehabil. 2010;24:614-22.

19. Kulkarni SR, Fletcher E, Mcconnell AK, Poskitt KR, Whyman MR. Preoperative inspiratory muscle training preserves postoperative inspiratory muscle strength following major abdominal surgery - a randomised pilot study. Ann R Coll Surg Engl. 2010;92:700-7.

20. Savci S, Degirmenci B, Saglam M, Arikan H, Inal-Ince D, Turan HN, et al Short-term effects of inspiratory muscle training in coronary artery bypass graft surgery: a randomized controlled trial. Scand Cardiovasc J. 2011;45: 286-93.

21. Heynen H, De Jonge C, Kerkkamp H, Willms J, Sosef M. Preconditioning in patients undergoing esophagectomy: a randomized controlled pilot study. Dis Esophagus. 2012;25:84A.

22. Dettling DS, Van Der Schaaf M, Blom RL, Nollet F, Busch OR, Van Berge Henegouwen MI. Feasibility and effectiveness of pre-operative inspiratory muscle training in patients undergoing oesophagectomy: a pilot study. Physiother Res Int. 2013;18:16-26.

23. Soares SM, Nucci LB, Da Silva MM, Campacci TC. Pulmonary function and physical performance outcomes with preoperative physical therapy in upper abdominal surgery: a randomized controlled trial. Clin Rehabil. 2013; 27:616-27.

24. Van Adrichem EJ, Meulenbroek RL, Plukker JT, Groen H, Van Weert E Comparison of two preoperative inspiratory muscle training programs to prevent pulmonary complications in patients undergoing esophagectomy: a randomized controlled pilot study. Ann Surg Oncol. 2014;21 2353-60.

25. Brocki BC, Andreasen JJ, Langer D, Souza DS, Westerdahl E. Postoperative inspiratory muscle training in addition to breathing exercises and early mobilization improves oxygenation in high-risk patients after lung cancer surgery: a randomized controlled trial. Eur J Cardiothorac Surg. 2016;49: 1483-91.

26. Eastwood PR, Hillman DR. A threshold loading device for testing of inspiratory muscle performance. Eur Respir J. 1995;8:463-6.

27. Kroenke K, Lawrence VA, Theroux JF, Tuley RM. Operative risk in patients with severe obstructive pulmonary disease. Arch Intern Med. 1992;152: 967-71.

28. Arozullah AM, Khuri SF, Henderson WG, Daley J. Development and validation of a multifactorial risk index for predicting postoperative pneumonia after major noncardiac surgery. Ann Intern Med. 2001;135:847-57.

29. Wada JT, Borges-Santos E, Porras DC, Paisani DM, Cukier A, Lunardi AC, et al Effects of aerobic training combined with respiratory muscle stretching on the functional exercise capacity and thoracoabdominal kinematics in patients with COPD: a randomized and controlled trial. Int J Chron Obstruct Pulmon Dis 2016;11:2691-700

30. Mans CM, Reeve JC, Elkins MR. Postoperative outcomes following preoperative inspiratory muscle training in patients undergoing cardiothoracic or upper abdominal surgery: a systematic review and meta analysis. Clin Rehabil. 2015; 29:426-38.

31. Gomes Neto M, Martinez BP, Reis HF, Carvalho VO. Pre- and postoperative inspiratory muscle training in patients undergoing cardiac surgery: systematic review and meta-analysis. Clin Rehabil. 2017;31:454-64. 
32. Kendall F, Oliveira J, Peleteiro B, Pinho P, Bastos PT. Inspiratory muscle training is effective to reduce postoperative pulmonary complications and length of hospital stay: a systematic review and meta-analysis. Disabil Rehabil. 2017; $17: 1-22$.
Key Words: inspiratory muscle training, preoperative care, postoperative pulmonary complications, systematic review 


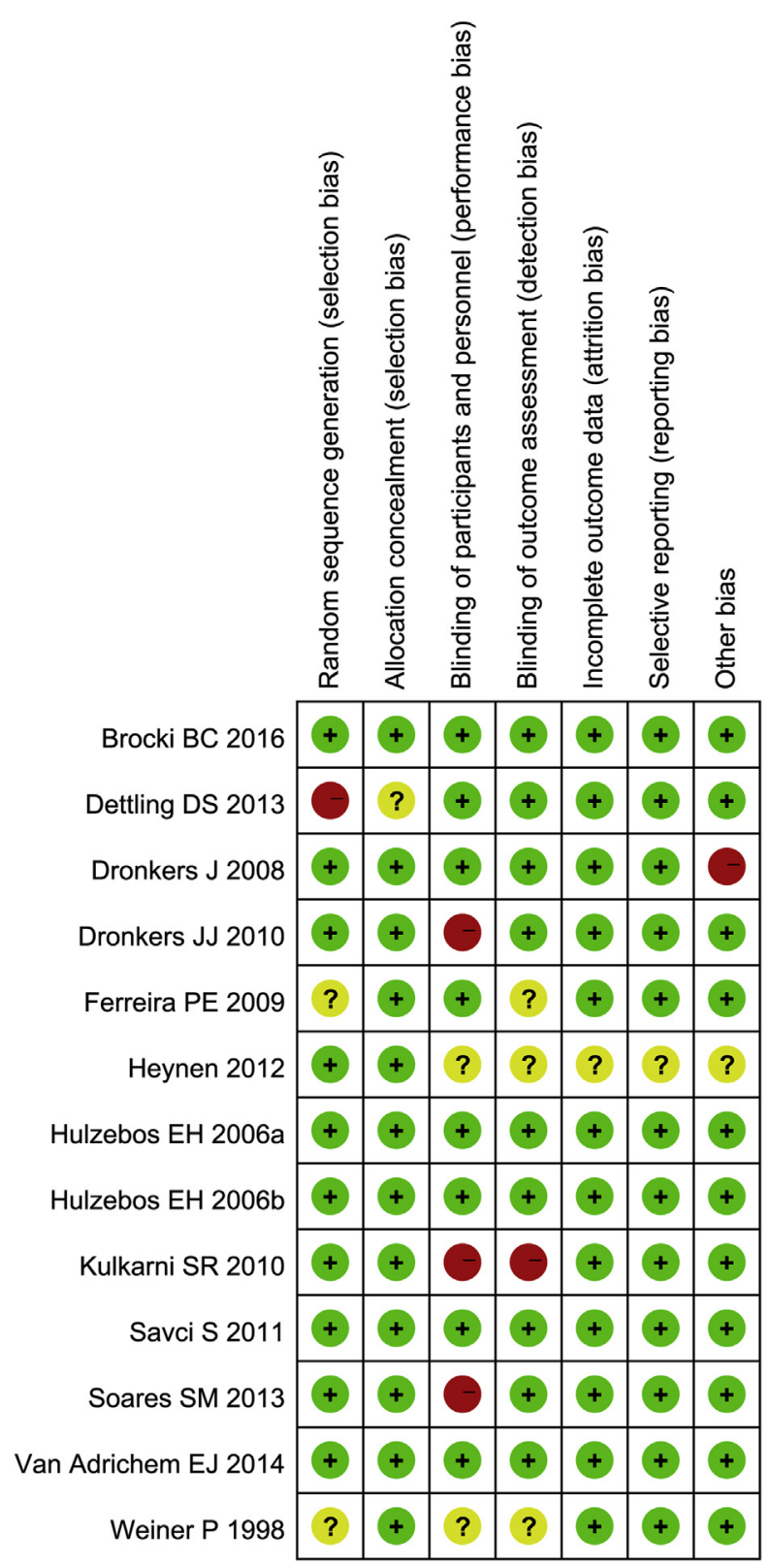

FIGURE E1. Risk of bias summary. 
TABLE E1. The preferred reporting items for systematic reviews and meta-analyses checklist (www.prisma-statement.org)

\begin{tabular}{|c|c|c|c|}
\hline Section/topic & \# & Checklist item & $\begin{array}{l}\text { Reported } \\
\text { on page \# }\end{array}$ \\
\hline \multicolumn{4}{|l|}{ Title } \\
\hline Title & 1 & Identify the report as a systematic review, meta-analysis, or both. & Page 1 \\
\hline \multicolumn{4}{|l|}{ Abstract } \\
\hline Structured summary & 2 & $\begin{array}{l}\text { Provide a structured summary including, as applicable: background; objectives; data } \\
\text { sources; study eligibility criteria, participants, and interventions; study appraisal and } \\
\text { synthesis methods; results; limitations; conclusions and implications of key findings; } \\
\text { systematic review registration number. }\end{array}$ & Page 3-4 \\
\hline \multicolumn{4}{|l|}{ Introduction } \\
\hline Rationale & 3 & Describe the rationale for the review in the context of what is already known. & Page 4 \\
\hline Objectives & 4 & $\begin{array}{l}\text { Provide an explicit statement of questions being addressed with reference to participants, } \\
\text { interventions, comparisons, outcomes, and study design. }\end{array}$ & Page 5 \\
\hline \multicolumn{4}{|l|}{ Methods } \\
\hline Protocol and registration & 5 & $\begin{array}{l}\text { Indicate if a review protocol exists, if and where it can be accessed (eg, web address), and, if } \\
\text { available, provide registration information including registration number. }\end{array}$ & No \\
\hline Eligibility criteria & 6 & $\begin{array}{l}\text { Specify study characteristics (eg, participants, interventions, comparisons, outcomes, and } \\
\text { study design and length of follow-up) and report characteristics (eg, years considered, } \\
\text { language, and publication status) used as criteria for eligibility, giving rationale. }\end{array}$ & Page 6 \\
\hline Information sources & 7 & $\begin{array}{l}\text { Describe all information sources (eg, databases with dates of coverage, contact with study } \\
\text { authors to identify additional studies) in the search and date last searched. }\end{array}$ & Page 5-6 \\
\hline Search & 8 & $\begin{array}{l}\text { Present full electronic search strategy for at least one database, including any limits used, } \\
\text { such that it could be repeated. }\end{array}$ & Table E2 \\
\hline Study selection & 9 & $\begin{array}{l}\text { State the process for selecting studies (ie, screening; eligibility; included in systematic } \\
\text { review; and, if applicable, included in the meta-analysis). }\end{array}$ & Page 6 \\
\hline Data collection process & 10 & $\begin{array}{l}\text { Describe method of data extraction from reports (eg, piloted forms, independently, in } \\
\text { duplicate) and any processes for obtaining and confirming data from investigators. }\end{array}$ & Page 6-7 \\
\hline Data items & 11 & $\begin{array}{l}\text { List and define all variables for which data were sought (eg, participants, interventions, } \\
\text { comparisons, outcomes, and study design and funding sources) and any assumptions and } \\
\text { simplifications made. }\end{array}$ & Page 7 \\
\hline $\begin{array}{l}\text { Risk of bias in individual } \\
\text { studies }\end{array}$ & 12 & $\begin{array}{l}\text { Describe methods used for assessing risk of bias of individual studies (including } \\
\text { specification of whether this was done at the study or outcome level), and how this } \\
\text { information is to be used in any data synthesis. }\end{array}$ & Page $7-8$ \\
\hline Summary measures & 13 & State the principal summary measures (eg, risk ratio, difference in means). & Page 8 \\
\hline Synthesis of results & 14 & $\begin{array}{l}\text { Describe the methods of handling data and combining results of studies, if done, including } \\
\text { measures of consistency }\left(\mathrm{eg}, I^{2}\right) \text { for each meta-analysis. }\end{array}$ & Page 8 \\
\hline Risk of bias across studies & 15 & $\begin{array}{l}\text { Specify any assessment of risk of bias that may affect the cumulative evidence } \\
\text { (eg, publication bias, selective reporting within studies). }\end{array}$ & Page 7-8 \\
\hline Additional analyses & 16 & $\begin{array}{l}\text { Describe methods of additional analyses (eg, sensitivity or subgroup analyses, } \\
\text { meta-regression), if done, indicating which methods were prespecified. }\end{array}$ & Page 8-9 \\
\hline \multicolumn{4}{|l|}{ Results } \\
\hline Study selection & 17 & $\begin{array}{l}\text { Give numbers of studies screened, assessed for eligibility, and included in the review, with } \\
\text { reasons for exclusions at each stage, ideally with a flow diagram. }\end{array}$ & Page 10 \\
\hline Study characteristics & 18 & $\begin{array}{l}\text { For each study, present characteristics for which data were extracted (eg, study size, PICOS, } \\
\text { follow-up period) and provide the citations. }\end{array}$ & Page 10 \\
\hline Risk of bias within studies & 19 & $\begin{array}{l}\text { Present data on risk of bias of each study and, if available, any outcome level assessment } \\
\text { (see Item 12). }\end{array}$ & Page 11 \\
\hline Results of individual studies & 20 & $\begin{array}{l}\text { For all outcomes considered (benefits or harms), present, for each study: simple summary } \\
\text { data for each intervention group and effect estimates and confidence intervals, ideally } \\
\text { with a forest plot. }\end{array}$ & Page $11-13$ \\
\hline Synthesis of results & 21 & $\begin{array}{l}\text { Present results of each meta-analysis done, including confidence intervals and measures of } \\
\text { consistency. }\end{array}$ & Page 11-13 \\
\hline Risk of bias across studies & 22 & Present results of any assessment of risk of bias across studies (see Item 15). & Page 11 \\
\hline Additional analysis & 23 & $\begin{array}{l}\text { Give results of additional analyses, if done (e., sensitivity or subgroup analyses, } \\
\text { meta-regression [see Item 16]). }\end{array}$ & Page 12 \\
\hline
\end{tabular}


TABLE E1. Continued

\begin{tabular}{|c|c|c|c|}
\hline Section/topic & $\#$ & Checklist item & $\begin{array}{l}\text { Reported } \\
\text { on page \# }\end{array}$ \\
\hline \multicolumn{4}{|l|}{ Discussion } \\
\hline Summary of evidence & 24 & $\begin{array}{l}\text { Summarize the main findings including the strength of evidence for each main outcome; } \\
\text { consider their relevance to key groups (eg, health care providers, users, and policy } \\
\text { makers). }\end{array}$ & Page 14-16 \\
\hline Limitations & 25 & $\begin{array}{l}\text { Discuss limitations at study and outcome level (eg, risk of bias), and at review-level } \\
\text { (eg, incomplete retrieval of identified research, reporting bias). }\end{array}$ & Page 16-17 \\
\hline Conclusions & 26 & $\begin{array}{l}\text { Provide a general interpretation of the results in the context of other evidence, and } \\
\text { implications for future research. }\end{array}$ & Page 17 \\
\hline \multicolumn{4}{|l|}{ Funding } \\
\hline Funding & 27 & $\begin{array}{l}\text { Describe sources of funding for the systematic review and other support } \\
\text { (eg, supply of data); role of funders for the systematic review. }\end{array}$ & Page 1 \\
\hline
\end{tabular}

Source: Moher D, Liberati A, Tetzlaff J, Altman DG, The PRISMA Group. Preferred Reporting Items for Systematic Reviews and Meta-Analyses: the PRISMA Statement. PLoS Med. 2009;6:e1000097. 
TABLE E2. Search strategies

Search strategy for PubMed

\#1. pre-surgical[Title/Abstract]

\#2. presurgical[Title/Abstract]

\#3. pre-operative[Title/Abstract]

\#4. preoperative[Title/Abstract]

\#6. "Preoperative Care"[Mesh]

\#7.\#1 OR \#2 OR \#3 OR \#4 OR \#6

\#8. IMT[Title/Abstract]

\#9. inspiratory muscle train[Title/Abstract]

\#10. respiratory train[Title/Abstract]

\#11. ventilatory train[Title/Abstract]

\#12. pulmonary train[Title/Abstract]

\#13. breathing train[Title/Abstract]

\#14. breathing exercises[Title/Abstract]

\#15. physical therapy modalities[Title/Abstract]

\#16. physiotherapy[Title/Abstract]

\#17. Respiratory therapy[Title/Abstract]

\#19. "Breathing Exercises"[Mesh]

\#20. \#8 OR \#9 OR \#10 OR \#11 OR \#12 OR \#13 OR \#14 OR \#15

OR \#16 OR \#17 OR \#19

\#21. \#7 AND \#20

Search strategy for Excerpta Medica database

\#1. 'pre-surgical':ab,ti

\#2. 'presurgical':ab,ti

\#3. 'pre-operative':ab,ti

\#4. 'preoperative': ab,ti

\#5. 'preoperative care'/exp

\#6. \#1 OR \#2 OR \#3 OR \#4 OR \#5

\#7. 'imt':ab,ti

\#8. 'inspiratory muscle train':ab,ti

\#9. 'respiratory train':ab,ti

\#10. 'ventilatory train':ab,ti

\#11. 'pulmonary train':ab,ti

\#12. 'breathing train':ab,ti

\#13. 'breathing exercises':ab,ti

\#14. 'physical therapy modalities':ab,ti

\#15. 'physiotherapy':ab,ti

\#16. 'respiratory therapy':ab,ti

\#17. 'breathing exercise'/exp

\#18. \#7 OR \#8 OR \#9 OR \#10 OR \#11 OR \#12 OR \#13 OR \#14

OR \#15 OR \#16 OR \#17

\#19. \#6 AND \#18

Search strategy for Web of Science

$\# 1$. pre-surgical[TOPIC]

\#2. presurgical[TOPIC]

\#3. pre-operative[TOPIC]

\#4. preoperative[TOPIC]

\#5. \#1 OR \#2 OR \#3 OR \#4

\#6. IMT[TOPIC]

\#7. inspiratory muscle train[TOPIC]

\#8. respiratory train[TOPIC]

$\# 9$. ventilatory train[TOPIC]

\#10. pulmonary train[TOPIC]

\#11. breathing train[TOPIC]

\#12. breathing exercises[TOPIC]

\#13. physical therapy modalities[TOPIC]

\section{TABLE E2. Continued}

\#14. physiotherapy[TOPIC]

$\# 15$. Respiratory therapy[TOPIC]

\#16. \#7 OR \#8 OR \#9 OR \#10 OR \#11 OR \#12 OR \#13 OR \#14 OR \#15

\#17. \#7 AND \#16

Search strategy for Cochrane Central Register of Controlled Trials

\#1 inspiratory muscle train or IMT:ti,ab or ventilatory train or pulmonary train:ti,ab

or breathing exercises:ti,ab

\#2 MeSH descriptor: [Breathing Exercises] explode all trees

\#3 MeSH descriptor: [Preoperative Care] this term only

\#4 \#1 or \#2 or \#3

\#5 pre-surgical or presurgical:ti,ab or pre-operative or preoperative \#6 MeSH descriptor: [Cardiac Surgical Procedures] this term only \#7 MeSH descriptor: [Coronary Artery Bypass] this term only \#8 MeSH descriptor: [Digestive System Surgical Procedures] this term only

$\# 10 \# 5$ or \#6 or \#7 or \#8

\#11 \#4 and \#10

Search strategy for Cumulative Index to Nursing and Allied Health

Literature

S1 ( (MH "inspiratory muscle train") OR (MH "respiratory train") OR (MH "Preoperative Care") OR (MH “IMT”) OR (MH

"ventilatory train") OR (MH "physiotherapy") OR (MH

"breathing exercise")

S2 ( (MH “pre-surgical”) OR (MH “presurgical”) OR (MH "pre-operative") OR (MH "preoperative)

S3 S1 and S2 
TABLE E3. The definition of postoperative pulmonary complications ${ }^{27}$

Grade 1

- Cough, dry.

- Microatelectasis: abnormal lung findings and temperature $>37.5^{\circ} \mathrm{C}$ without other documented cause; results of chest radiograph either normal or unavailable.

- Dyspnea, not due to other documented cause.

Grade 2

- Cough, productive, not due to other documented cause.

- Bronchospasm: New wheezing or preexistent wheezing resulting in change therapy.

- Hypoxemia: Alveolar-arterial gradient $>29$ and symptoms of dyspnea or wheezing.

- Atelectasis: Radiologic confirmation plus either temperature $>37.5^{\circ} \mathrm{C}$ or abnormal lung findings.

- Hypercarbia, transient, requiring treatment such as naloxone or increased manual or mechanical ventilation.

- Adverse reaction to pulmonary medication.

Grade 3

- Pleural effusion resulting in thoracentesis.

- Pneumonia, suspected: Radiologic evidence without bacteriologic confirmation.

- Pneumonia, proved: Radiologic evidence and documentation of pathologic organism by Gram stain or culture.

- Pneumothorax.

- Reintubation postoperative or intubation, period of ventilator dependence does not exceed $48 \mathrm{~h}$.

Grade 4

- Ventilatory failure: Postoperative ventilator dependence exceeding $48 \mathrm{~h}$ or reintubation with subsequent period of ventilator dependence exceeding $48 \mathrm{~h}$. 